\title{
Effect of Gas Permeability of Porous LSM Cathode on Low Frequency Impedance Plots
}

\author{
Tomoo MOTOKI, Tatsuru NAMIKAWA and Yohtaro YAMAZAKI*
}

Received July 31, 1996; Accepted October 18, 1996

\section{INTRODUCTION}

Solid oxide fuel cells (SOFCs) directly convert the free energy of fuel gas to electric energy. Many efforts have been made on SOFCs to reduce operating temperature because it widens the choice of alloy cell stack materials. The cost of production of SOFC stacks will be reduced considerably by the use of conventional heat resistant alloys. Preparation of high quality electrolyte thin films on porous support electrodes is the present objective to achieve the advancement of low temperature operating cells. A thick porous electrode is indispensable to a thin film cell, because the electrode supports a thin fragile electrolyte film. The concentration polarization in such thick electrodes must be considered in the operation of the thin film cells at high current densities. The gas permeability, porosity and bending strength of porous $\mathrm{La}(\mathrm{Sr}) \mathrm{MnO}_{3}$ (LSM) cathode prepared by the extrusion-sintering method, were measured at Fujikura Ltd. ${ }^{1)}$ And the investigation about gas diffusion behavior in LSM substrate using AC impedance method was reported by Osaka Gas Co.Ltd.' However, details in electrochemical properties of thick porous LSM cathodes have not been investigated.

In this study, we prepare porous thick LSM electrodes by sintering, and the electrochemical properties of the clectrode on YSZ electrolyte plate are investigated by AC impedance method. The concentration polarization of $\mathrm{O}_{2}$ in the electrode is studied in connection with the porosity and gas permeability of the electrode.

\section{EXPERIMENTAL}

Two LSM powders were used for the preparation of thick porous LSM cathode which have various porosities. ${ }^{3)}$ One was as purchased powder of $\mathrm{La}_{0.9} \mathrm{Sr}_{0.1} \mathrm{MnO}_{3}$ (ATD Co.), and the other powder was prepared by thermally treating the purchased powder at $1550^{\circ} \mathrm{C}$ in air

Department of Electronic Chemistry, Interdisciplinary Graduate School of Science and Engineering, Tokyo Institute of Technology (4259 Nagatsuta, Midori-ku, Yokohama 226, Japan)

Key Words : SOFC, LSM Cathode, Porous Electrode, AC Impedance Measurement for $3 \mathrm{~h}$ to increase the grain size. The two powders were mixed with various weight ratios of $1 / 1,1 / 5$ and $0 / 1$. One $\mathrm{ml}$ of $1 \mathrm{wt} \%$ aqueous solution of polyvinylalcohol $(n=1500-1800)$ was added to $10 \mathrm{~g}$ of each mixed LSM powder. The powder was pressed with a pressure of $8.62 \times 10^{7} \mathrm{~Pa}$ to form a disk $(2.6 \mathrm{~mm}$ thick, $18 \mathrm{~mm}$ in diameter). The pressed disks were fired at $1400{ }^{\circ} \mathrm{C}$ for $3 \mathrm{~h}$ in air. The diameter of thick porous LSM cathodes was about $18 \mathrm{~mm}$ and the thickness was $2.60 \mathrm{~mm}$. The porosities were $9.5,28,53$ and $56 \%$ for the various mixing ratios of the two LSM powders. The gas permeability coefficient of the LSM cathodes was determined by measuring the flow rate of permeated air through the samples. The mesurement was made at room temperature with a pressure difference of $1.0 \times 10^{4} \mathrm{~Pa}$. The gas permeability coefficients of these LSM cathodes were $<1.0 \times 10^{-6}, 3.0 \times 10^{-4}, 7.0 \times 10^{-3}$ and $2.0 \times 10^{-2} \mathrm{~cm}^{4} \mathrm{~g}^{-1}$ $\mathrm{sec}^{-1}$, respectively.

Each LSM cathode was stuck on a $0.25 \mathrm{~mm}$ thick $8 \mathrm{YSZ}$ plate (8mol\% $\mathrm{Y}_{2} \mathrm{O}_{3}-\mathrm{ZrO}_{2}$, TOSOH Co., TZ-8Y) with $\mathrm{Pt}$ paste, and heated at $900^{\circ} \mathrm{C}$ for $2 \mathrm{~h}$ in air. A Pt electrode was prepared on the opposite side of the YSZ plate by screen printing. The Pt electrode was used as anode.

The correlation between the impedance of the cathode reaction and the gas permeability coefficient of each porous cathode was investigated by using the $\mathrm{AC}$

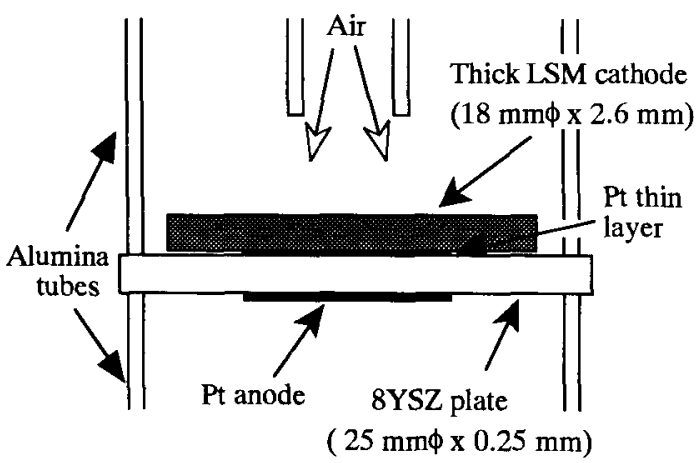

Fig.1 Cell configuration. 

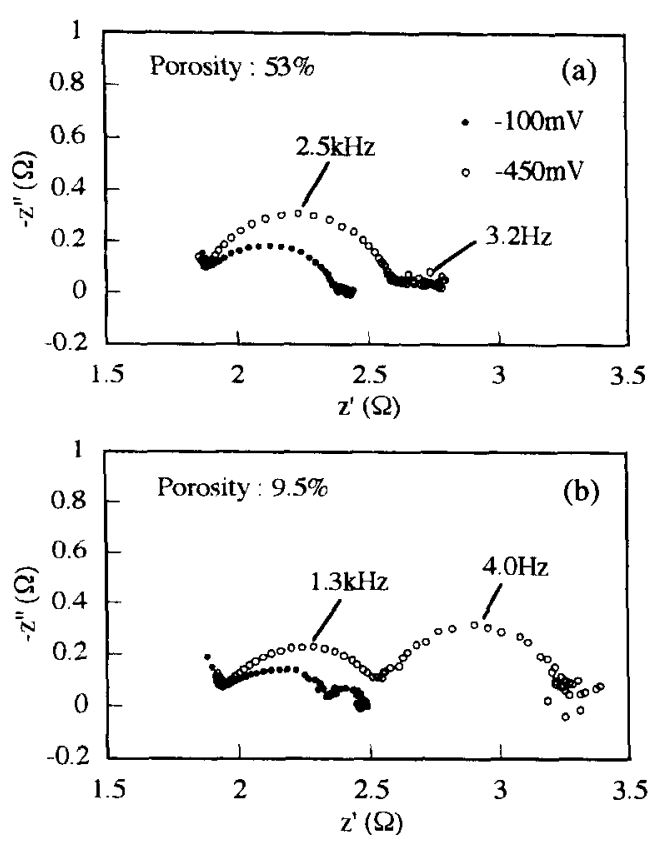

Fig.2 AC impedance plots for porous thick LSM cathode with 8 YSZ electrolyte, porosity of electrode : (a) $53 \%$, (b) $9.5 \%$.

impedance method. The cell was mounted between two alumina tubes (Fig.1). Air flowed down to the cathode with a rate of $50 \mathrm{ml} \mathrm{min} \mathrm{m}^{-1}$. Anode was only exposed to air. The measurement was made at $900{ }^{\circ} \mathrm{C}$ in air. The potential differences of 100 and $450 \mathrm{mV}$ were applied between the cathode and anode. The impedance of the cells was measured with the AC voltage of $\pm 10 \mathrm{mV}$ in the frequency range from 0.01 to $10^{5} \mathrm{~Hz}$. An impedance response analyzer (NF Electonic Instruments 5080) was used for the measurement.

\section{RESULTS AND DISCUSSION}

Figures 2 (a) and (b) show the impedance plots for the cathodes with the porosities of $9.5 \%$ and $53 \%$. Two semicircles are observed in high frequency region and low frequency region. Both semicircles enlarged when the overpotential increased from $100 \mathrm{mV}$ to 450 $\mathrm{mV}$.

Impedance measurement was also made, for comparison, with a Pt/ YSZ/ Pt cell without the LSM cathode. The result showed one semicircle in the high frequency region. This semicircle includes the impedance relating to the grain boundaries of the electrolyte and the finite length diffusions of oxide ion at anode and cathode interfaces. When measurement was made with porous thick LSM cathodes, the second semicircle appeared in low frequency region. Therefore, these second semicircles are expected to correspond to the finite length

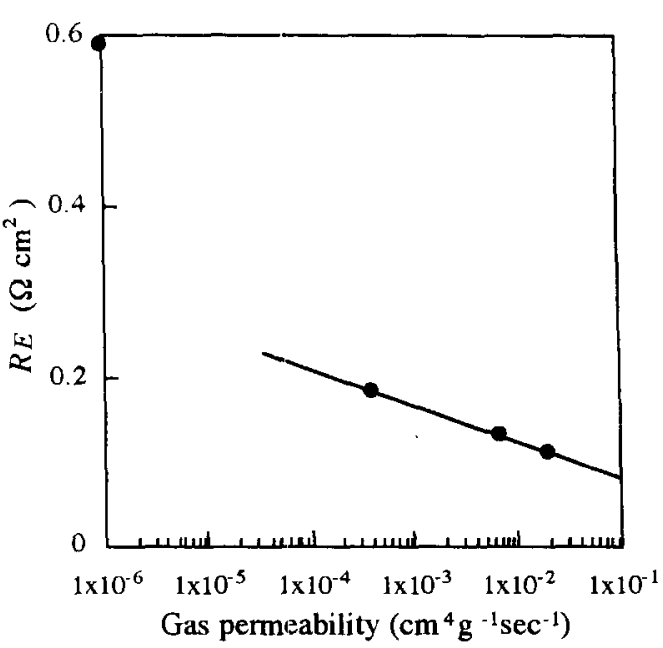

Fig.3 Impedance for electrode reaction $\left(R_{E}\right)$ as a function of the gas permeability coefficient of electrode material.

diffusion of $\mathrm{O}_{2}$ gas in the porous thick LSM cathode. The intercept of the second semicircle is represented as $R_{E}$. The value of $R_{E}$ was normalized with the electrode area. The relationship between $R_{E}$ and gas permeability coefficient is shown in Fig.3. $R_{E}$ decreased when the porosity and gas permeability coefficient increased.

Because the values of Fig. 3 in the region of gas permeability coefficient from $10^{-4}$ to $10^{-1}$ are relatively low, we can expect that the concentration polarization in the porous thick LS.M cathodes does not severely confine the functions of thin film high temperature fuel cells.

\section{CONCLUSIONS}

An AC impedance analysis was made on LSM electrodes with various porosities and gas permeabilities, in order to study the polarization in porous thick LSM cathodes which are necessary for thin film SOFCs. It was found that the polarization in conjunction with the gas transport in the thick electrode could be detected as a semicircle in a low frequency region near $4.0 \mathrm{~Hz}$ in the AC impedance plot.

The impedance of electrode reaction which was estimated from the impedance plot in the low frequency region, was related linearly to the logarithm of gas permeability of electrode material.

\section{REFERENCES}

1) M. Nagata, C. Iwasawa, S. Yamaoka, Y. Seino and M. Ono, Proc. of 4th Int. Symp. on SOFCs, p. 173, Yokohama, ECS (1995).

2) M. Suzuki, T. Sogi, A. Kajimura and H. Sasaki, Proc. of 2nd FCDIC Fuel Cell Symp., p. 185, (1995).

3) T.Ide, T. Namikawa ard Y. Yamazaki, Denki Kagaku, 64, 681 (1996). 